\title{
ALGORITHMS FOR PRACTICAL LABORATORY MODELS
}

\author{
DOBIAS, M[ichal] \& PIVONKA, P[etr]
}

\begin{abstract}
This paper deals with the verification of algorithms designed for laboratory models whose core is the microprocessor and an uncertainty which will be later included for robust control trainings. There are currently two models: DC motor and Water tank. In this article these two model are verified and currently there is an attempt to develop the DC motor with the heating equation. The summarizing publication of this area is (Churchhouse et al., 1981; Greenspan \& Rozsa, 1988).

This work selects appropriate models and numerical methods which will subsequently be implemented in the PLC. This solution will enable expanding the laboratory with another working compartment.
\end{abstract}

Key words: numerical methods, discrete approximation, laboratory models, PI controller, LQ controller

\section{INTRODUCTION}

In the eighties of this century there has been significant progress in the development of computer technology and the application of microprocessors has reached a wide range of use. New methods of programming allowed more efficient and quicker development of applications. The most common applications are personal computers, cell phones, in the industry there are the PLCs, Servodrives, HMI, etc. One of the atypical applications is the microchip as a laboratory refund for the real physical system, which can have unsuitable properties for the laboratory use (size, energy consumption, malicious content, and long response times)

\section{CONTROLLER}

PI controller, or more precisely, the discrete equivalent (Landau \& Zito, 2006) is the most commonly used controller in practice. It is popular for its simplicity, the possibility of intuitive setup of parameters, and also for the wide range of possible method setup.

$$
\boldsymbol{F}_{\boldsymbol{R}}(z)=K\left[1+\frac{T z^{-1}}{\boldsymbol{T}_{I}\left(1-z^{-1}\right)}\right]
$$

Quadratic optimal controller (LQ) is in its basic form state controller with proportional feedback of system status. The matrix obtained is then optimally chosen to the defined criterion (Skogestad \& Postlethwaite, 2009) Controller is modified for reference tracking and zero control error $\left(Q_{\text {se }}\right.$ penalizing sum of control error).

$$
J=\frac{1}{2} x^{T} Q x+u^{T} R u
$$

Relay controller is one of the oldest methods of regulation. By its means it is especially easy to control pressure and temperature. It is an inexpensive alternative of control. These controllers are robust to system parameters changes and are capable of controlling nonlinear systems.

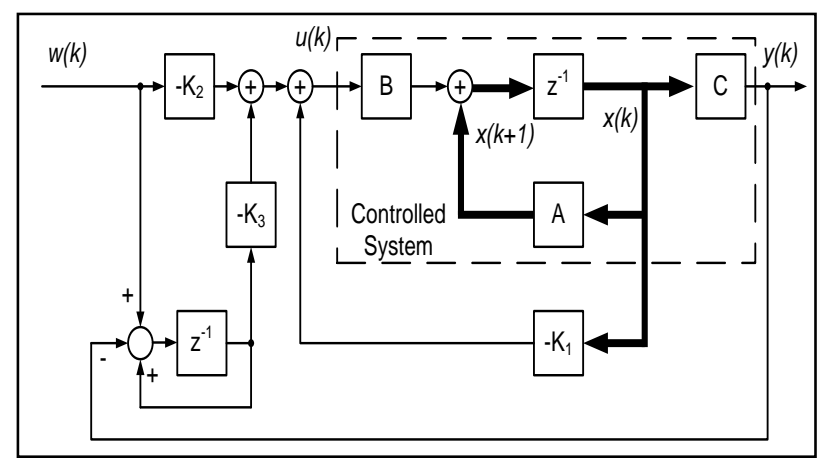

Fig. 1. Modification of LQ controller

\section{MODELS}

DC motor and Water tank were chosen as the models of real systems. Their mathematical descriptions were discretized and by the use of a numerical method implemented as discrete models, which will be in the next part of the work placed in the microchip.

\subsection{DC motor}

For simulations we use a DC motor with separate excitation. The equations describing its function are:

$$
u_{m}=R_{m} i_{m}+L_{m} \frac{d i_{m}}{d t}+k \omega
$$

And for radial speed

$$
J \frac{d \omega}{d t}=M_{m}-M_{z}=k i_{m}-M_{z}
$$

Euler's method is used for the numerical solution whith the Taylor's expansion in this form (Butcher, 2003):

$$
y_{i+1}=y_{i}+f\left(x_{i}, y_{i}\right) h+\frac{f^{\prime}\left(x_{i}, y_{i}\right)}{2} h^{2}
$$

\subsection{Water tank}

The model of Water tank is described by this diferential equation:

$$
A \frac{d h}{d t}=w-k a \sqrt{2 g h}
$$

The model contains nonlinearity which is the reason why we usel a relay controller (Svarcr, 2005). Numerical solution is achieved by using standard Euler's method (Butcher, 2003):

$$
y_{i+1}=y_{i}+f\left(x_{i}, y_{i}\right) h
$$




\section{SIMULATIONS}

All simulations, computations and results are obtained with MATLABSimulink and have an illustrative character.

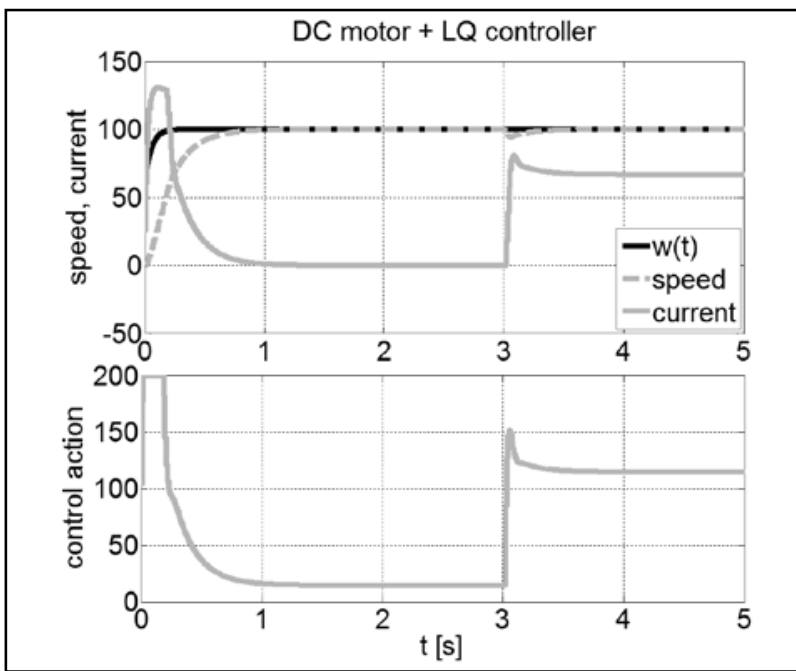

Fig. 2. DC motor control with LQ controller $\left(Q=1, Q_{\mathrm{se}}=0.003, R=0.0005\right)$

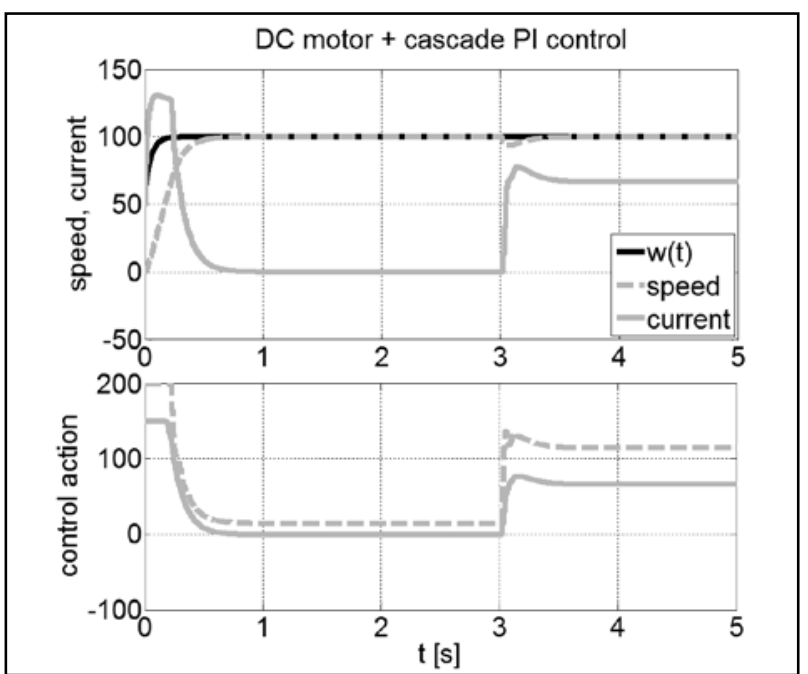

Fig. 3. DC motor control with cascade PI control (current controller $K=3.5, T_{\mathrm{I}}=0.4$; speed controller $K=9, T_{\mathrm{I}}=2$ )

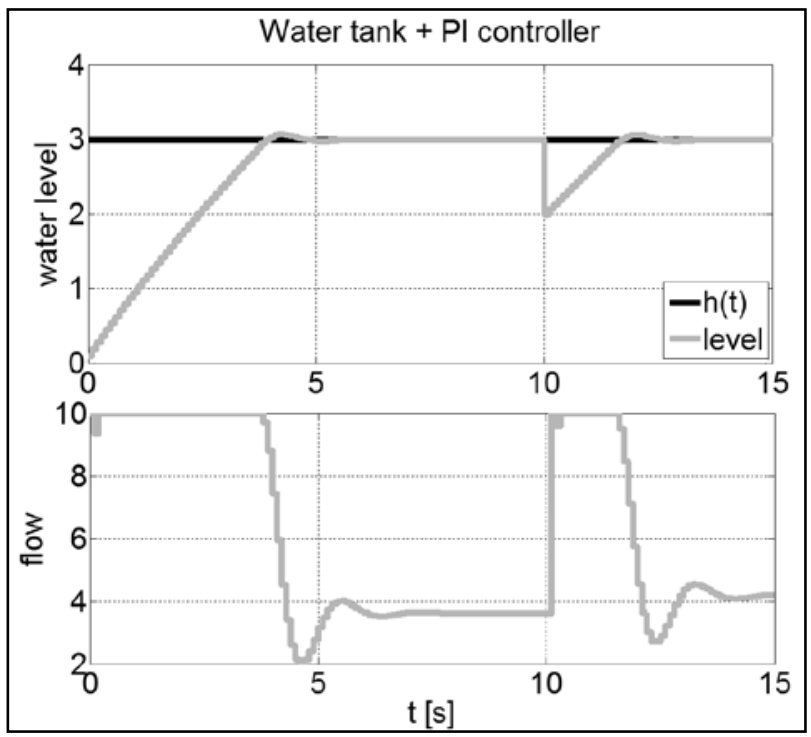

Fig. 4. Water tank control with PI controller $\left(K=40, T_{\mathrm{I}}=0.3\right)$

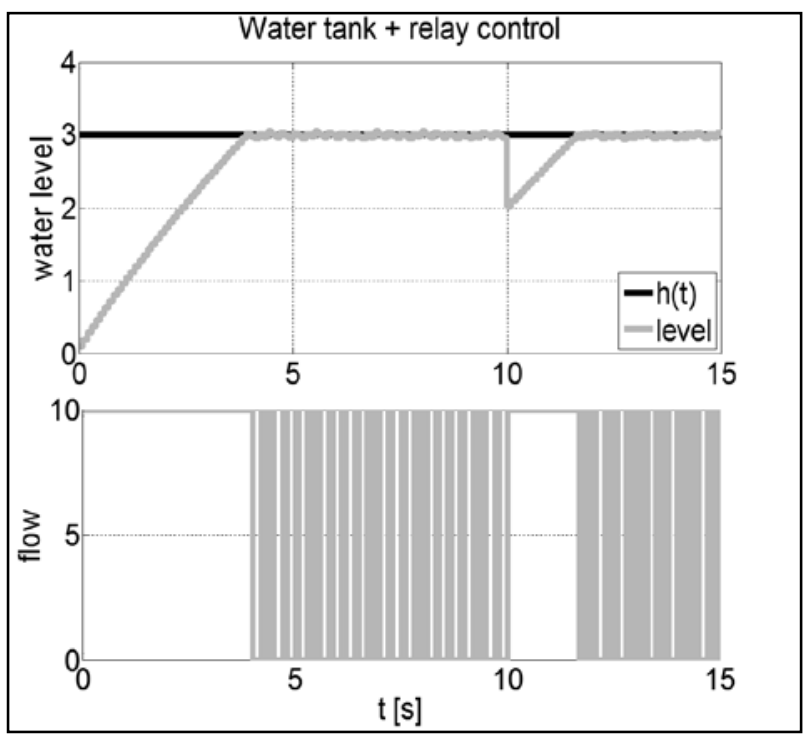

Fig. 5. Water tank control with relay (switching area (0.02; 0.007))

\section{CONCLUSION}

The aim of this work was to design and implement algorithms for laboratory models whose core is the microprocessor. Presented algorithms have been tested for the step stepresponse, and also for the step disturbance on the output system (the disturbance is active at the time $3 \mathrm{~s}$ for DC motor and $10 \mathrm{~s}$ for Water tank). Presented algorithms have satisfactory behavior. Simulation for DC motor runs with sampling time $0.01 \mathrm{~s}$ and the Water tank has the sampling period $0.1 \mathrm{~s}$. The only drawback is the inaccurate approximation of the initial steps of calculation. This problem will by solved in future work. The advantage of this solution is the possibility of acceleration of the simulation for systems with long time constants, which will be used in further work. Later research will have the aim of finding suitable algorithm of the heated swimming pool with solar panels and the application with constrained predictive control.

\section{ACKNOWLEDGEMENTS}

This work has been supported by the Fund for the development of universities, no. 1247/G1 "Practical models for verification of modern controllers".

\section{REFERENCES}

Butcher, J. C. (2003). Numerical Methods for Ordinary Differential Eguations. John Wiley \& Sons, ISBN 0-47196758-0, Chichester

Churchhouse, R. F.; Cohen, A. M.; Jones, D. E.; Khabaza, I. M.; Rogers, M. H. \& Turner, P. R. (1981). Handbook of Applicable Mathematics: Numerical Methods, Vol.3. John Wiley \& Sons, ISBN 047127947 1, Binghamon

Greenspan, D. \& Rozsa, P. (1988). Numerical Methods. HortHolland, ISBN 044470209 1, Amsterdam

Landau, I.,D. \& Zito, G. (2006). Digital Control Systems: Design, Identification and Implementation. Springer, ISBN 978-1-84628-055-9, London

Postlethwaite, I. \& Skogestad, S. (2009). Multivariable Feedback Control. John Wiley \& Sons, ISBN 978-0-47001168-3, Chichester

Svarcr, I. (2005). Automatizace: Automaticke rizeni. Brno University of Technology, ISBN 80-214-2943-7, Brno 